ISSN 1518-3483

Licenciado sob uma Licença Creative Commons

\title{
Aprendizagem em/na rede: comunidades virtuais de aprendizagem em blogs
}

\author{
Online learning: virtual communities in blogs
}

\section{Patrícia Brandalise Scherer Bassani ${ }^{[a]}$, Rosi Souza Fritz ${ }^{[b]}$}

[a] Doutora em Informática na Educação pela Universidade Federal do Rio Grande do Sul (UFRGS), professora titular do Programa de Pós-Graduação em Diversidade Cultural e Inclusão Social da Universidade Feevale, coordenadora do Grupo de Pesquisa em Informática na Educação da mesma instituição, Novo Hamburgo, RS - Brasil, e-mail: patriciab@feevale.br

[b] Mestre em Inclusão Social e Acessibilidade pela Universidade Feevale, professora do curso de Turismo da mesma instituição, Novo Hamburgo, RS - Brasil, e-mail: rosifritz@feevale.br

\section{Resumo}

Os blogs consistem em suportes para a comunicação mediada por computador, permitindo a interação, a colaboração e a socialização on-line, caracterizando-se como espaços virtuais que possibilitam a constituição de comunidades virtuais. No contexto educacional, constituem importante recurso para escrita coletiva e aprendizagem colaborativa, oportunizando a comunicação e o trabalho em grupo, promovendo o processo de autoria na internet. Estudos atuais apontam que a aprendizagem on-line acontece por meio das comunidades virtuais de aprendizagem. A partir dessa perspectiva, este estudo busca investigar a formação de comunidades virtuais de aprendizagem em blogs, tendo sido realizado a partir da análise da interação por meio das trocas de comentários e links postados em um 
blog. Os resultados apontam as especificidades de uma comunidade virtual de aprendizagem e o potencial da ferramenta blog para a aprendizagem colaborativa na internet.

Palavras-chave: Comunidade virtual. Comunidade virtual de aprendizagem. Blog.

\section{Abstract}

Blogs consist of support for computer mediated communication and allow interaction, collaboration and online socialization. They are characterized as virtual spaces that enable the constitution of virtual communities. In the educational context, blogs are an important resource to collective writing and collaborative learning, making possible the communication and group work, and promoting authorship process in the Internet. Present studies point out that online learning happens in virtual learning communities. Through this perspective, this study focuses on research about the constitution of virtual learning communities in blogs. The study involved the analysis of the interaction through the exchange of comments and links posted in a blog. The results show the specificities of virtual learning communities and the potential of the tool blog for collaborative learning on Internet.

Keywords: Virtual communities. Virtual learning communities. Blog.

\section{Introdução}

Os blogs são ferramentas de manutenção e publicação de sites, constituídas por mensagens (também chamadas postagens ou posts), comentários, ilustrações, fotografias, sons e vídeos, organizados de forma inversa, porém temporal, sendo as postagens mais recentes colocadas no topo da página. Os primeiros blogs, conhecidos como weblogs (web+log = arquivo web), surgiram em $1997^{1}$ e passaram a ser utilizados de forma crescente. Estudos sobre eles vêm se intensificando ao longo dos anos; segundo Amaral, Recuero e Montardo (2009), o que chama atenção é o

1 Amaral, Recuero e Montardo (2009) apresentam um histórico da criação dos weblogs. 
fato de que uma ferramenta que já possui mais de dez anos na web mantenha-se atual no cotidiano das pessoas. As autoras apontam ainda que a "versatilidade em ser apropriado para as mais variadas tarefas" (p. 23) contribui para sua permanência na rede.

Conforme Lemos (2008), os blogs vêm se transformando em um dos mais populares fenômenos da cibercultura ${ }^{2}$. Segundo o autor, eles

são criados para os mais diversos fins, refletindo um desejo reprimido pela cultura de massa: o de ser ator na emissão, na produção de conteúdo e na partilha de experiências. Os blogs refletem a liberação do pólo da emissão característico da cibercultura (LEMOS, 2008, p. 9).

A característica de "liberação do pólo da emissão" apontada por Lemos (2008, p. 9), somada à facilidade de utilização, classifica o blog como um software social, que pode se transformar em um instrumento de aproximação dos sujeitos na produção cultural, possibilitando a construção do conhecimento testemunhado por diversos olhares. Consoante Spyer (2007, p. 21), “o termo 'social software' é usado para se referir ao tipo de programa que produz ambientes de socialização pela internet, ele é que está por trás da colaboração online", como blogs, microblogs, wikis, compartilhamento de arquivos e outros. Assim, o blog pode ser entendido como uma ferramenta que busca oportunizar ações colaborativas, criando um comprometimento entre quem escreve, quem lê e quem comenta, provocando aprendizado.

Gutierrez (2003) destaca as possibilidades dessa ferramenta no espaço educacional, entendendo que ela se torna instrumento de reflexão e de comparação na construção do conhecimento. Conforme a autora,

2 Cibercultura é apresentada como uma marca da cultura contemporânea, cujo imaginário e práticas convergem para uma relação mais intensa entre homens e máquinas, sugerindo novos hábitos cotidianos e novas formas de socialização por meio da comunicação mediada por computador (LÉVY, 1999; LEMOS, 2008). 
essa oportunidade de reflexão sobre seus pensamentos e suas práticas, de comparar etapas de processos, é importantíssima para professores e alunos. O acompanhamento do trabalho de alunos e colegas conscientiza sobre a própria prática. O conteúdo dinâmico de um weblog pode manter o registro da construção do conhecimento e de suas fases e abrir espaço para a investigação (GUTIERREZ, 2003, p. 95).

Entretanto, Gutierrez (2003, p. 95) destaca a importância de compreender que a informação e o conhecimento são coisas distintas e que "o computador, a internet e as possibilidades de acesso à informação oportunizada pelas tecnologias digitais, são necessários, mas não suficientes para a construção do conhecimento".

Os blogs, que inicialmente eram utilizados como diários públicos na internet, com o tempo e a massificação de uso, foram recebendo outras características e funções. De acordo com Recuero (2003), eles podem ser utilizados como publicações eletrônicas que se destinam à informação, comentários, crônicas e contos ou como publicações mistas, que englobam os diários íntimos e diversas informações. Primo e Smaniotto (2006, p. 233) também fazem uso dos conceitos apresentados pela autora, principalmente quando indicam que "é preciso ultrapassar-se a noção do blog como texto e espaço individual, como celebração do ego no ciberespaço".

Pelo exposto, percebe-se que os blogs deixam de ser apenas publicações pessoais para se tornar potencializadores de ações construídas coletivamente entre os sujeitos que compartilham esse espaço. Compreendendo-os como ferramentas de comunicação e, consequentemente, de interação social, este trabalho busca refletir sobre as possibilidades de constituição de Comunidades Virtuais de Aprendizagem (CVAs) em blogs.

O estudo inicia-se a partir da criação de um blog de escrita coletiva entre duas turmas de quarto ano de duas escolas da rede pública de Novo Hamburgo (RS). A partir das reflexões iniciais sobre os conceitos de comunidade virtual, faz-se o estudo dos blogs como ferramentas potenciais na formação de CVAs. 


\section{Comunidades virtuais e CVAs}

O termo 'comunidade' remete a agrupamentos que se sentem unidos por algum tipo de sentimento de pertença, seja no sentido geográfico, por proximidade territorial, seja em uma perspectiva extraterritorial, pela busca de interesses comuns. O desenvolvimento tecnológico, especialmente a disseminação do acesso à internet, permitiu novas formas de comunicação entre as pessoas, de localidades próximas ou distantes, oportunizando a criação de uma nova comunidade, sem base territorial. Assim, no fim do século XX e início do século XXI, percebe-se a consolidação do conceito de comunidades virtuais (BAUMAN, 2003; CASTELLS, 2003).

Para Rheingold (1996, p. 18), "as comunidades virtuais são os agregados sociais surgidos na Rede, quando os intervenientes de um debate o levam por diante em número e sentimento suficientes para formarem teias de relações sociais no ciberespaço". Recuero (2008, p. 65) ressalta que

o conceito de comunidade virtual é uma tentativa de explicar os agrupamentos sociais surgidos no ciberespaço. Trata-se de uma forma de tentar entender a mudança da sociabilidade, caracterizada pela existência de um grupo social que interage através da comunicação mediada pelo computador.

Castells (2003), por sua vez, apresenta a noção de comunidades virtuais como novos suportes tecnológicos para a sociabilidade, diferentes de outras formas de interação, mas não inferiores. Destaca, também, que elas trabalham com base em duas características fundamentais comuns:

a) valor da comunicação livre, horizontal, caracterizada pela comunicação on-line de muitos para muitos;

b) formação autônoma de redes, que envolve a possibilidade de qualquer pessoa escolher/definir os fluxos de navegação na rede, além do potencial de criar e divulgar suas próprias redes. 
Recuero (2009) disserta que as comunidades virtuais na internet são reconhecidas a partir de três diferentes tipos: comunidades de associação, comunidades emergentes e comunidades híbridas. Uma comunidade emergente caracteriza-se por um núcleo mais denso, no qual estão os atores conectados por nós ${ }^{3}$ mais fortes, e uma periferia, na qual estão os nós mais fracos. Assim, "os laços que conectam os atores na comunidade emergente são fortes no centro e fracos na periferia" (p. 154). Entretanto, destaca-se a dinâmica dessas comunidades, uma vez que os laços "podem estar fortalecendo-se e encaminhando-se em relação ao núcleo ou enfraquecendo-se e afastando-se do mesmo" (p. 154). As comunidades de associação (ou de filiação) caracterizam-se essencialmente pela "associação de atores através de interação social reativa (associar-se ao grupo e ser aceito pelo mesmo), que não pressupõe interação direta entre os atores, ou mesmo interação social no sentido de conversação" (p. 156). Por fim, as comunidades híbridas possuem características dos dois tipos (emergentes e associativas).

As comunidades virtuais com foco na aprendizagem podem ser classificadas em CVAs ou Comunidades de Prática (CPs) (DANIEL; SCHWIER; MCCALLA, 2003; PALOFF; PRATT, 2002). A principal diferença entre elas consiste na natureza da participação dos sujeitos: enquanto a CVA enfoca objetivos educacionais, a CP enfatiza o compartilhamento de experiências e interesses relacionados a atividades profissionais. Embora toda comunidade virtual tenha relação com um elemento de aprendizagem, nem toda comunidade pode ser chamada CVA, pois esta implica que seus membros tenham objetivos explícitos vinculados à aprendizagem (DANIEL; SCHWIER; MCCALLA, 2003).

Paloff e Pratt (2002) sustentam que a CVA constitui o espaço onde se dá a aprendizagem on-line. As autoras apontam alguns indicadores de que uma comunidade on-line está em formação:

3 Cada ponto da rede. 
a) interação ativa em relação ao conteúdo do curso e à comunicação interpessoal, ou seja, para que um aluno seja considerado "presente" em aula, não basta acessar a aula, é preciso participar enviando suas reflexões/ideias;

b) aprendizagem colaborativa, percebida por meio das trocas de mensagens e/ou comentários entre os alunos e entre estes e o professor;

c) significado construído socialmente, evidenciado a partir de discussões envolvendo acordos ou questionamentos, à medida que a aula/curso desenvolve-se;

d) compartilhamento de recursos (livros, artigos encontrados na internet, fontes de pesquisa) entre alunos, possibilitando ampliar a bibliografia para além dos textos selecionados pelo professor;

e) troca de expressões de estímulo entre alunos e vontade de avaliar criticamente os trabalhos dos colegas.

Schwier (2007) também aponta categorias para analisar a formação das CVAs. De acordo com o autor, elas podem ser entendidas a partir de três níveis. Um primeiro nível constitui o núcleo central (Catalysts of Virtual Learning Communities), que impulsiona a formação e a continuidade da comunidade. Seu elemento principal é a comunicação entre os participantes da comunidade, aliada ao senso de presença/participação, à interação, ao engajamento e ao alinhamento. A segunda categoria, que constitui um núcleo intermediário (Emphases of Virtual Learning Communities), representa a ênfase da CVA, que pode ser classificada em comunidades de relacionamento, de lugar, de intenção, de reflexão ou de cerimônia. Um terceiro nível, externo (Elements of Virtual Learning Communities), constitui-se a partir de 13 elementos, enfatizando a ideia de que as comunidades são complexas. Os elementos são: historicidade, identidade, mutualidade, pluralidade, autonomia, participação, confiança, trajetória, tecnologia, protocolos sociais, reflexão, intensidade e aprendizagem. Assim, seus estudos apontam que as comunidades não acontecem de forma espontânea, mas também não são 
criadas. Essas categorias buscam orientar os educadores a promover o desenvolvimento das CVAs.

Neste estudo, entende-se que o blog, como espaço constituído por relações que ocorrem entre os interagentes ${ }^{4}$, pode ser considerado um meio para a formação dessas comunidades. Entretanto, o fato de um blog receber vários visitantes não fornece subsídios para a criação de uma comunidade. "Em outras palavras, não se pode pensar que um blog, por ter muitos visitantes diários, seja por si só uma comunidade" (PRIMO; SMANIOTTO, 2006, p. 237). Nesse caso, para compreender a constituição de uma CVA em um blog, deve-se analisar a qualidade da relação entre os interagentes (PRIMO; SMANIOTTO, 2006; RECUERO, 2009).

De acordo com Recuero (2009), a interação representa um processo comunicacional, que é refletido nos sujeitos que interagem e no resultado dessas trocas comunicativas. Primo (2003) caracteriza dois tipos de interação mediada por computador: interação mútua e interação reativa.

A interação mútua é aquela caracterizada por relações interdependentes e processos de negociação, em que cada interagente participa da construção inventiva e cooperada da relação, afetando-se mutuamente; já a interação reativa é limitada por relações determinísticas de estímulo e resposta (PRIMO, 2003, p. 63).

A interação mútua não pode ser predeterminada, visto que a relação somente é definida no decorrer da própria interação. Já a interação reativa caracteriza-se por as trocas acontecerem dentro de limites previstos, ou seja, a partir dos mesmos inputs, há os mesmos outputs. Primo (2007) considera, ainda, que a interação mútua é construída a partir das relações anteriores, porque um interagente contribui na formação do outro. Assim, ela vem ao encontro do pensamento de que as comunidades consolidam-se a partir das negociações e dos laços que se formam.

4 Primo (2003) entende interação como "ação entre" os participantes do encontro, que são por ele definidos como interagentes. 
Os laços sociais são entendidos como a efetiva interação entre os participantes de uma relação, podendo ser fortes ou fracos. Laços fortes caracterizam-se pela proximidade, intimidade e intencionalidade em manter a conexão com o outro; por outro lado, os laços fracos caracterizam-se por relações esparsas, que não traduzem intimidade e proximidade. Entende-se que a análise das interações em uma CVA a partir dos laços sociais implica perceber a relevância tanto dos laços fortes quanto dos laços fracos na constituição e permanência da comunidade (BASSANI, 2011). Em um blog, os laços podem ser percebidos pela ferramenta comentários. Assim, os comentários geram os laços, que acabam por se transformar no capital social produzido por determinados sujeitos que interagem. Recuero (2009) destaca que o capital social na internet constitui um conjunto de recursos de um determinado grupo, que pode ser usufruído por todos os membros e está baseado na reciprocidade.

A partir dos elementos teóricos apresentados, percebe-se que as CVAs apresentam especificidades em relação às comunidades virtuais, uma vez que enfatizam a aprendizagem em espaços educacionais formais. Downes (2007), nesse sentido, destaca que a atividade de aprendizagem nas comunidades é, em essência, a conversação entre os sujeitos participantes, que, para o autor, não consiste apenas em palavras, mas imagens, vídeo, som e outros. Entretanto, este estudo foca a linguagem escrita, a partir das mensagens postadas no blog e seus comentários, conforme descrito na seção seguinte.

\section{$O$ percurso de pesquisa}

Conforme dito anteriormente, este estudo ${ }^{5}$, de abordagem qualitativa, inicia-se a partir da criação de um blog de escrita coletiva en-

5 O presente estudo constitui um recorte da dissertação de mestrado Desenvolvimento do turismo local por meio da participação comunitária: a constituição de uma comunidade virtual em um blog (FRITZ, 2010). 
tre duas turmas de quarto ano de duas escolas da rede pública de Novo Hamburgo, que serão tratadas aqui como Escola A e Escola B. As turmas participantes compreendem uma faixa etária entre oito e 14 anos, sendo que 23 alunos pertencem à Escola A e 28, à Escola B, perfazendo um total de 51 alunos.

O tema das discussões coletivas foi o estudo do fenômeno do turismo no bairro das escolas, enfatizando aspectos culturais e naturais. O blog Novos Roteiros Turísticos em Novo Hamburgo ${ }^{6}$ foi utilizado para criar um espaço de trocas de informações turísticas entre as escolas, buscando identificar novos locais que pudessem ser explorados turisticamente, permitindo que os alunos vissem seu bairro como um espaço que também oferece atratividade na cidade, fomentando sua autoestima como moradores da localidade. Ao longo da pesquisa, foram realizadas 44 postagens, que resultaram em 103 comentários.

\section{Reflexões sobre a formação da comunidade virtual}

A pesquisa oportunizou um primeiro contato dos estudantes com a ferramenta blog, tendo sido possível perceber que a apropriação tecnológica da ferramenta constitui importante aspecto na formação de uma comunidade virtual.

O blog representa uma comunidade do tipo híbrida, articulando características das comunidades emergentes, em que as interações acontecem a partir das trocas sociais realizadas pela conversação explicitada nas mensagens, e das comunidades de associação, uma vez que a ferramenta possibilita que um determinado sujeito seja "seguidor" do blog, sem necessariamente participar efetivamente em sua autoria. Sua apropriação foi percebida por dois aspectos: criação de novas redes e construção da identidade na comunidade. Assim, a apropriação da ferramenta impulsionou a criação de novos blogs, transcendendo limites e

6 O blog está disponível em <http://www.turismonomeubairro.blogspot.com>. 
ampliando as possibilidades de comunicação, conforme Castells (2003), e oportunizando a interação entre os sujeitos das Escolas A e B além do espaço escolar. A construção da identidade na rede, por sua vez, foi evidenciada nas assinaturas das postagens e, principalmente, na ferramenta comentários. Na proposta inicial, cada escola/turma recebeu uma senha e as postagens ficavam registradas como Escola A ou Escola B. Entretanto, à medida que os alunos foram descobrindo o potencial do blog, as postagens começaram a ser personalizadas, apresentando o registro da autoria (nome e foto do aluno).

Conforme Schwier (2007), a interação em uma comunidade normalmente resulta em engajamento de ideias, pessoas e processos; no caso do blog, ela se dá a partir dos comentários vinculados a uma determinada postagem. Ao se observar a conversação entre os sujeitos, percebem-se evidências de aprendizagem colaborativa e socialização de conhecimentos, que refletem um processo de interação mútua. Nesse caso, a interação é definida ao longo do processo de trocas comunicacionais; no entanto, à medida que os sujeitos disponibilizam uma informação em uma ferramenta social, é impossível prever o tipo de situação comunicacional que será gerado dessa interação, conforme apresentado na postagem (Quadro 1).

De acordo com Schwier (2007), a intensidade de uma CVA manifesta-se a partir do envolvimento e participação na discussão, o que é possível verificar no recorte da conversa apresentado. Além disso, o sentimento de pertença e a vivência em redes sociais podem produzir confiança. De fato, as relações de confiança constituem importante elemento na permanência das CVAs, potencializando a formação de laços sociais e as trocas significativas.

A análise das conexões estabelecidas no blog evidenciou os laços sociais entre as Escolas A e B, entre os alunos e entre os diferentes blogs individuais construídos por meio da apropriação da ferramenta. A Figura 1 apresenta a rede social constituída pelas interações produzidas no blog. Conforme dito anteriormente, as primeiras postagens estavam vinculadas a uma senha única (Professoras 1, 2 e 3); a apropriação da ferramenta possibilitou a personalização das postagens, evidenciada 


\section{Quadro 1 - Exemplo de interação mútua evidenciada no blog}

\begin{tabular}{|c|c|}
\hline Postagem & Comentários \\
\hline $\begin{array}{l}\text { Visita ao Hotel Locanda } \\
\text { No dia 28/04/09 nós fomos no } \\
\text { Locanda Hotel, que fica na rua } \\
\text { Wendelino Henrique Klazer. } \\
\text { Conhecemos os funcionários } \\
\text { do hotel, como a camareira, a } \\
\text { recepcionista e o gerente do hotel, } \\
\text { Sr. Ricardo. Eles nos levaram a } \\
\text { vários locais, como a piscina, a } \\
\text { sauna, nos quartos dos hóspedes. } \\
\text { Fomos também até academia, a } \\
\text { sala de conferência. Aprendemos } \\
\text { muitas coisas sobre turismo e sobre } \\
\text { como receber as pessoas como ser } \\
\text { hospitaleiro. }\end{array}$ & $\begin{array}{l}\text { - Vocês podem me explicar o que é camareira? Mauricio } \\
\text { - Oi, gostaria de saber mais sobre a visita até o Hotel. } \\
\text { Gostaria de saber mais sobre a piscina e a profe Rosi } \\
\text { falou que tem uma sala de ginástica. Aguardo a resposta. } \\
\text { Michele vitoria ludwig Affonso Penna } \\
\text { - Oi gente como é o nome da sua professora? } \\
\text { o hotel é legal? } \\
\text { - Oi, como foi conhecer o gerente do hotel? Como e o seu } \\
\text { nome? Vocês já tinham ido dentro de algyum hotel? Suélen } \\
\text { - Ola pessoal sou Julia Machado. Mas estou bem feliz } \\
\text { e estou ansiosa quando vocês vierem na nossa escola } \\
\text { Affonso Penna. Adorei o hotel que vocês foram e queremos } \\
\text { também conhecer o hotel, adorei!!!. } \\
\text { Quero saber o que è a palavra hospitaleiro? Alias eu adorei } \\
\text { a piscina tchau tchau pessoal. JÚLIA M. } \\
\text { - Eu queria saber o que é sauna? Laura } \\
\text { - ola eu sou a juliane adorei o hotel e é bem bonito e eu } \\
\text { não sabia que ele existia. JULIANE } \\
\text { - eu queria ver mais fotos do hotel. Ânderson } \\
\text { - Gostei muito de ler sobre o hotel,deve ser legal entrar no } \\
\text { quarto dos hospedes e falar com os funcionaríos! Júlia .B. } \\
\text { - oi pessoal, quanto custa ficar um dia no hotel ? Fernanda K. } \\
\text { - OLA EU SOU O DIONATA EU GOSTEI MUITO DAS FOTOS. } \\
\text { - A visita ao hotel foi legal? Eu gostaria de ir lá... Fernanda G. } \\
\text { - ola queria saber o que quer dizer sala de conferência? } \\
\text { Obrigada, lera Izaname Martins Berté } \\
\text { - Oi, gostamos muito do hotel, é bem bonito. Então, o } \\
\text { hotel é luxuoso? GABRIELI CRISTINI DA SILVA E ALEXANDRA } \\
\text { CAMILA CASSEL. } \\
\text { - Para ficar um dia no HOTEL é } 100 \text { reais. barato NE } \\
\text { - Oi pessoal respondendo a sua pergunta camareira é uma } \\
\text { pessoa que arruma os quartos do hotel. } \\
\text { - Humm Sim achamos o HOTEL muito luxuoso. Acho que } \\
\text { vocês tambem deveriam conhecer. Thiago e Augusto. } \\
\text { - Olá Matheus o nome da nossa Profa é Ana Lucia. } \\
\text { O Hotel é bem legal. Thiago e Augusto } \\
\text { - Respondendo a pergunta de vocês: Sauna é uma salinha } \\
\text { para relaxar e descansar, com vapor quente. Rafael e Nicolas. } \\
\text { - O hotel Locanda é muito legal a gente até comeu um xis. } \\
\text { thau pessoal até logo } \\
\text { - O nome do gerente é Ricardo. Ele é bem legal!! }\end{array}$ \\
\hline
\end{tabular}

Fonte: Dados da pesquisa. ${ }^{7}$

7 Informações disponíveis em <http://www.turismonomeubairro.blogspot.com.br/2009/05/visitaao-hotel-locanda-no-dia-280409.html\#comment-form>. 
nas interações entre os alunos das Escolas A e B e o blog. A figura também permite visualizar relações externas com a comunidade e outros blogs, evidenciadas por meio dos comentários.

O fato de o blog ter características assíncronas, ou seja, os sujeitos não precisam estar conectados o tempo todo para interagir, favorece o aprendizado, permitindo a reflexão e posterior intervenção. Algumas postagens permaneceram no blog por um longo tempo sem comentários, mas, na medida em que houve interesse, os sujeitos comentaram a respeito do assunto. Assim, outro aspecto percebido é o seu potencial como novo espaço para ensinar e aprender.

Estudos atuais apontam que o ciberespaço suporta tecnologias intelectuais que amplificam, exteriorizam e modificam numerosas funções cognitivas, como a memória, a imaginação, a percepção e o raciocínio

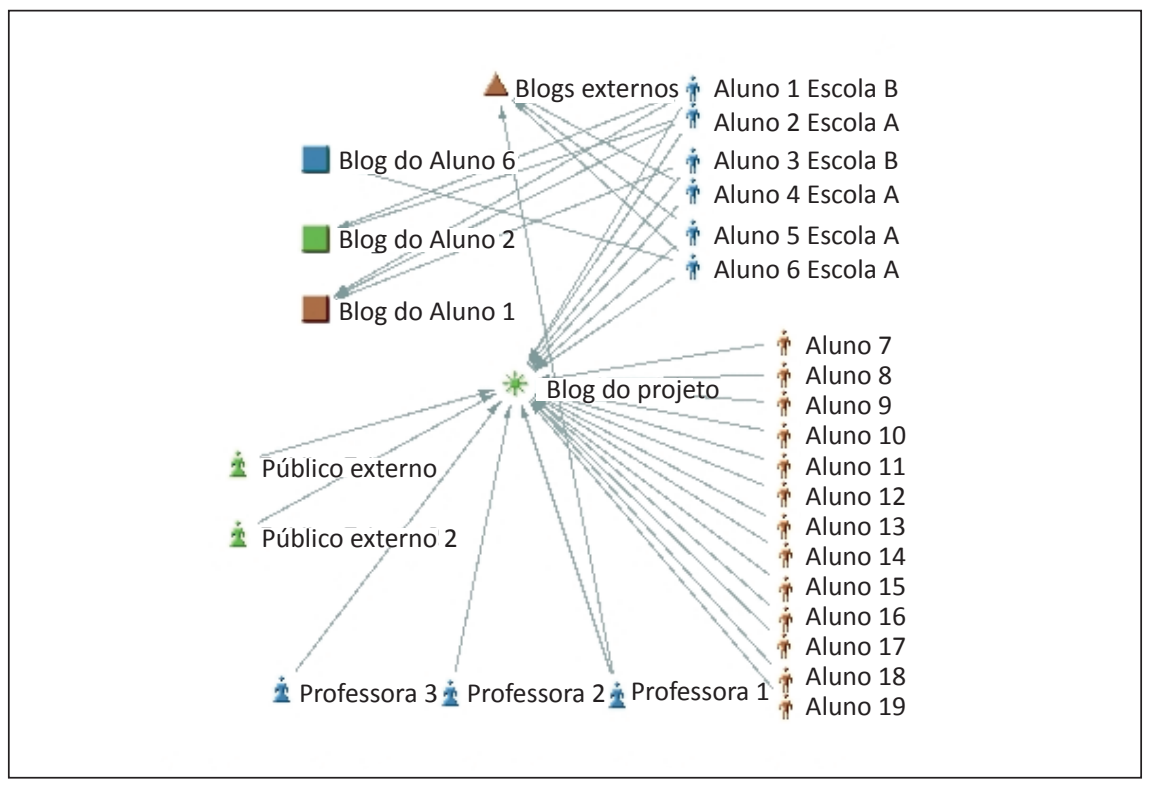

Figura 1 - Rede social

Fonte: FRITZ, 2010. 
(ALAVA, 2002; LÉVY, 2001). Essas novas “tecnologias intelectuais” favorecem novas formas de acesso à informação, por meio de mecanismos de pesquisa, hiperdocumentos ou agentes, além de novos estilos de raciocínio e conhecimento, envolvendo a simulação/modelação de fenômenos complexos ou ainda recursos de inteligência artificial. Além disso, por meio do ciberespaço, essas tecnologias podem ser compartilhadas, potencializando o que Lévy (2000) entende como inteligência coletiva. Para o autor, inteligência coletiva é "uma inteligência distribuída por toda a parte, incessantemente valorizada, coordenada em tempo real, que resulta em uma mobilização efetiva das competências" (p. 28).

Nas reflexões sobre educação no ciberespaço, Alava (2002) entende que este não pode ser reduzido a um espaço tecnológico que permite assegurar melhor a transmissão passiva do saber, mas deve ser entendido como um espaço social de comunicação e de trabalho em grupo. $\mathrm{O}$ autor entende que o saber não é um produto pré-construído e midiaticamente distribuído, mas resultado de um trabalho de construção individual ou coletivo, a partir de informações ou situações midiaticamente concebidas para oferecer oportunidades de mediação. Ressalta, ainda, que a emergência de novos dispositivos de formação abertos tende a colocar em pauta as ideias de trabalho colaborativo, autonomia dos estudantes e métodos ativos. Assim, "[...] a tecnologia da rede determina uma profunda mudança das relações sociais, assim como da organização de inúmeras atividades humanas. Tal evolução poderia levar a mecanismos de partilha, de colaboração, de gestão coletiva e de cognição distribuída” (p. 47).

Destaca-se então que, com a utilização dos blogs, os sujeitos têm a oportunidade de exercitar a autoria na rede em vez de apenas consultar/visitar sites, tornando-se emissores de conteúdos, segundo Lemos (2008), uma vez que podem produzir informações e construir conhecimento sob diversos olhares. Neste trabalho, a "velha" redação sobre "como foi meu passeio" deu lugar a uma exposição multimídia com fotos, filmes e sons, que pode ser compartilhada e (re)visitada em diferentes momentos, dentro e fora do espaço escolar. 


\section{Considerações finais}

Retomando o conceito delineado por Rheingold (1996, p. 44), que aponta que as comunidades virtuais são "agregados sociais surgidos na Rede", pode-se verificar a diferença na origem de uma comunidade virtual e uma CVA. Enquanto a primeira tem origem em interesses particulares, a segunda nasce a partir de uma proposta pedagógica, com objetivos específicos voltados para questões educativas. Nessa perspectiva, percebe-se o desafio em manter o envolvimento dos sujeitos em uma CVA, pois nem sempre os interesses particulares estão sintonizados com as propostas de sala de aula.

A análise do blog Novos Roteiros Turísticos em Novo Hamburgo à luz dos indicadores apontados por Paloff e Pratt (2002) permitiu caracterizá-lo como uma CVA, tendo sido possível verificar a existência de interação ativa, aprendizagem colaborativa, significado construído socialmente, compartilhamento de recursos e troca de expressões de estímulo entre alunos e vontade de avaliar criticamente os trabalhos dos colegas. As características que mais se destacaram foram aquelas relacionadas à autonomia dos sujeitos para construir o seu aprendizado e ao compartilhamento dessas descobertas com os sujeitos da outra escola.

Também foi possível identificar os três níveis das categorias apontadas por Schwier (2007) para analisar a formação das CVAs, sendo a comunicação entre os sujeitos apontada pelo autor como "o coração" da comunidade, ou seja, é a comunicação que mantém a comunidade. Nessa perspectiva, o autor destaca que as tecnologias facilitam o desenvolvimento das comunidades, mas também podem inibir o seu crescimento. A experiência comprovou a facilidade de uso da ferramenta, apontada por Amaral, Recuero e Montardo (2009), sendo apropriada pelos diversos públicos, no caso, crianças e jovens.

Importante destacar que a comunidade não se manteve por conta própria quando o projeto finalizou, destacando o importante papel do professor como articulador das ações coletivas. Fica evidente, dessa forma, que a CVA está intimamente relacionada ao trabalho escolar e tende 
a não se manter sem a presença do professor. Entretanto, somente a presença do professor não garante o sucesso de uma CVA; ele pode propor a atividade, solicitar o envolvimento, mas são os alunos que irão determinar a efetividade dessa comunidade.

Em resumo, as redes criam uma estrutura que permite o compartilhamento de informação, mas é preciso a proposição de novas práticas educacionais no ciberespaço que potencializem inovações pedagógicas para a construção de saberes a partir do coletivo.

\section{Referências}

ALAVA, S. (Org.). Ciberespaço e formações abertas: rumo a novas práticas educacionais? Porto Alegre: Artmed, 2002.

AMARAL, A.; RECUERO, R. C.; MONTARDO, S. P. (Org.). Blogs.com: estudos sobre blogs e comunicação. São Paulo: Momento Editorial, 2009.

BASSANI, P. B. S. Uma reflexão sobre os processos de mediação em um fórum de discussão a partir da análise de redes sociais. In: CONGRESSO INTERNACIONAL ABED DE EDUCAÇÃO A DISTÂNCIA, 17., 2011, Manaus. Anais eletrônicos... Manaus: ABED, 2011. Disponível em: <http://www.abed.org.br/congresso2011/ cd/130.pdf $>$. Acesso em: 5 set. 2013.

BAUMAN, Z. Comunidade: a busca por segurança no mundo atual. Rio de Janeiro: Jorge Zahar, 2003.

CASTELLS, M. A galáxia da internet: reflexões sobre a internet, os negócios e a sociedade. Rio de Janeiro: Jorge Zahar, 2003.

DANIEL, B.; SCHWIER, R. A.; MCCALLA, G. Social capital in virtual learning communities and distributed communities of practice. Canadian Journal of Learning and Technology, v. 29, n. 3, p. 113-139, Fall 2003. 
DOWNES, S. Learning networks in practice. In: BECTA (Ed.). Emerging technologies for learning. Conventry: Becta, 2007. v. 2. p. 19-27. Disponível em: <http:// webarchive.nationalarchives.gov.uk/20101102103654/http:/research.becta.org.uk/ index.php?section=rh\&catcode=_re_rp_02\&rid=13768 >. Acesso em: 5 set. 2013.

FRITZ, R. S. Desenvolvimento do turismo local por meio da participação comunitária: a constituição de uma comunidade virtual em um blog. 2010. $134 \mathrm{f}$. Dissertação (Mestrado em Inclusão Social e Acessibilidade) - Universidade Feevale, Novo Hamburgo, 2010.

GUTIERREZ, S. S. O fenômeno dos weblogs: as possibilidades trazidas por uma tecnologia de publicação na internet. Informática na Educação: Teoria \& Prática, v. 6, n. 1, p. 87-100, jan./jun. 2003.

LEMOS, A. Cibercultura, tecnologia e vida social na cultura contemporânea. 4. ed. Porto Alegre: Sulina Universitária, 2008.

LÉVY, P. Cibercultura. São Paulo: 34, 1999.

LÉVY, P. A inteligência coletiva: por uma antropologia do ciberespaço. São Paulo: Loyola, 2000.

LÉVY, P. A conexão planetária: o mercado, o ciberespaço, a consciência. São Paulo: 34, 2001.

PALLOFF, R. M.; PRATT, K. Construindo comunidades aprendizagem no ciberespaço: estratégias eficientes para as salas de aula on-line. Porto Alegre: Artmed, 2002.

PRIMO, A. F. T. Interação mediada por computador: a comunicação e a educação a distância segundo uma perspectiva sistêmico-relacional. 2003. 292 f. Tese (Doutorado em Informática na Educação) - Universidade Federal do Rio Grande do Sul, Porto Alegre, 2003.

PRIMO, A. F. T. Interação mediada por computador: comunicação, cibercultura, cognição. Porto Alegre: Sulina, 2007. 
PRIMO, A.; SMANIOTTO, A. Comunidades de blogs e espaços conversacionais. Prisma.com, n. 3, p. 230-272, 2006. Disponível em: <http://revistas.ua.pt/index.php/prismacom/article/view/631>. Acesso em: 18 set. 2013.

RECUERO, R. C. Warblogs: os weblogs, o jornalismo online e a Guerra no Iraque. Verso e Reverso, São Leopoldo, n. 37, p. 57-76, 2003.

RECUERO, R. C. Comunidades em redes sociais na internet: um estudo de caso dos fotologs brasileiros. Liinc em Revista, v. 4, n. 1, p. 63-83, mar. 2008.

RECUERO, R. C. Redes sociais na internet. Porto Alegre: Sulina, 2009.

RHEINGOLD, H. A comunidade virtual. Lisboa: Gradiva, 1996.

SCHWIER, R. A. A typology of catalysts, emphases and elements of virtual learning communities. In: LUPPICINI, R. (Ed.). Online learning communities. Charlotte: Information Age Publishing, 2007. p. 17-39.

SPYER, J. Conectado: o que a internet fez com você e o que você pode fazer com ela. Rio de Janeiro: Jorge Zahar, 2007.

Recebido: 03/09/2010

Received: 09/03/2010

Aprovado: 25/01/2011

Approved: 01/25/2011 